\title{
INOVAÇÃO CURRICULAR NO CONTEXTO UNIVERSITÁRIO: A EXPERIÊNCIA DO CURSO MAGISTÉRIO INDIGENA TREMEMBÉ SUPERIOR
}

\author{
INNOVACIÓN CURRICULAR EN EL CONTEXTO UNIVERSITARIO: LA \\ EXPERIENCIA DEL CURSO MAGISTERIO INDÍGENA TREMEMBÉ SUPERIOR
}

\author{
CURRICULAR INNOVATION IN THE UNIVERSITY CONTEXT: THE \\ EXPERIENCE OF THE SUPERIOR TREMEMBÉ INDIGENOUS MAGISTERIUM \\ COURSE
}

\author{
Adriana CAMPANI ${ }^{1}$ \\ Rejane Maria Gomes da SILVA ${ }^{2}$ \\ Paulina Maria Mendes PARENTE ${ }^{3}$
}

RESUMO: As políticas de ampliação e interiorização do ensino superior, assim como as das ações afirmativas, estimulam o acesso de indivíduos e grupos representantes da diversidade cultural constituinte da sociedade à universidade, o que gera uma atmosfera de multiculturalidade, e desafia os modelos epistemológicos tradicionais estruturantes da maioria dos currículos que dão base para práticas, procedimentos pedagógicos e construção de conhecimentos neste contexto educacional. Reconhece-se que desafios como esses evocam inovação pedagógica na universidade, e esta requer construções curriculares democráticas que favoreçam a interculturalidade e a inclusão social. Este artigo tem como objetivo apresentar uma discussão sobre inovação curricular no contexto universitário a partir da análise dos dados da pesquisa sobre os princípios e procedimentos do processo de construção e desenvolvimento curricular do Curso Magistério Indígena Tremembé Superior-MITS. A pesquisa teve abordagem qualitativa, com pesquisa documental, entrevistas em grupo focal, e observação participante em encontros com a comunidade Tremembé. O processo de construção e desenvolvimento curricular do MITS evidenciou o protagonismo de um grupo étnico específico, cooperativo e colaborativo, que desafiou a universidade a reconhecer novas autorias na perspectiva da produção do conhecimento. Provocou rupturas com as amarras do modelo tradicional de currículo universitário, incorporando a dimensão sócio-histórica do conhecimento, gerando possibilidades de diálogos interculturais entre a cultura acadêmica e a cultura Tremembé, sendo, por fim, considerada uma experiência de inovação pedagógica no contexto universitário.

PALAVRAS-CHAVE: Inovação pedagógica. Currículo. Interculturalidade. Universidade.

\footnotetext{
${ }^{1}$ Universidade Estadual Vale do Acaraú (UVA) Sobral - CE - Brasil. Doutora, Professora do Curso de Pedagogia da UVA. Membro do OIIIPE. ORCID: <https://orcid.org/0000-0002-4524-7694>. E-mail: campaniadriana@gmail.com

${ }^{2}$ Universidade Estadual Vale do Acaraú (UVA) Sobral - CE - Brasil. Doutora, Professora do Curso de Pedagogia da UVA. Membro do OIIIPE. ORCID: <https://orcid.org/0000-0003-2215-0686>. E-mail: rejanemgs@gmail.com

${ }^{3}$ Universidade Estadual Vale do Acaraú (UVA) Sobral - CE - Brasil. Doutora, Professora do Curso de Pedagogia da UVA. Membro do OIIIPE. ORCID: <https://orcid.org/0000-0001-6101-0016>. E-mail: paulinaparente@hotmail.com
} 
RESUMEN: Las políticas de ampliación e interiorización de la enseñanza superior, así como las de las acciones afirmativas, estimulan el acceso de individuos y grupos representantes de la diversidad cultural constituyente de la sociedad a la universidad, lo que genera una atmósfera de multiculturalidad y desafía los modelos epistemológicos tradicionales estructurantes de la mayoría de los currículos que dan base a prácticas, procedimientos pedagógicos y construcción de conocimientos en este contexto educativo. Se reconoce que desafíos como estos, evocan la innovación pedagógica en la universidad y ésta requiere construcciones curriculares democráticas que favorezcan la interculturalidad y la inclusión social. Este artículo tiene como objetivo presentar una discusión sobre innovación curricular en el contexto universitario a partir del análisis de los datos de la investigación sobre los principios y procedimientos del proceso de construcción y desarrollo curricular del Curso Magisterio Indígena Tremembé Superior MITS. La investigación tuvo un enfoque cualitativo, con investigación documental, entrevistas en grupo focal, y observación participante en encuentros con la comunidad Tremembé. El proceso de construcción y desarrollo curricular del MITS evidenció el protagonismo de un grupo étnico específico, cooperativo y colaborativo que desafió a la universidad a reconocer nuevas autorías en la perspectiva de la producción del conocimiento. Se produjo rupturas con las ataduras del modelo tradicional de currículo universitario incorporando la dimensión socio-histórica del conocimiento, generando posibilidades de diálogos interculturales entre la cultura académica y la cultura Tremembé, siendo finalmente considerada una experiencia de innovación pedagógica en el contexto universitario.

PALABRAS CLAVE: Innovación pedagógica. Currículo. Interculturalidad. Universidad.

ABSTRACT: The policies of expansion and internalization of higher education, as well as those of affirmative actions, stimulate the access of individuals and groups representing the cultural diversity that constitutes society to the university, which generates an atmosphere of multiculturality and challenges the traditional epistemological models structuring of most of the curricula that provide the basis for practices, pedagogical procedures and knowledge construction in this educational context. It is recognized that challenges such as these evokes pedagogical innovation in the university and this requires democratic curricular constructions that favor interculturality and social inclusion. This article aims to present a discussion on curricular innovation in the university context based on the analysis of research data on the principles and procedures of the process of construction and curriculum development of the Superior Tremembe Indigenous Magisterium Course - MITS. The research had a qualitative approach, with documentary research, focus group interviews, and participant observation in meetings with the Tremembe community. The process of construction and curriculum development of the MITS showed the protagonism of a specific ethnic, cooperative and collaborative group that challenged the university to recognize new authorship in the perspective of knowledge production. It provoked ruptures with the moorings of the traditional model of university curriculum incorporating the socio-historical dimension of the knowledge, generating possibilities of intercultural dialogues between the academic culture and the Tremembe culture, being finally considered an experience of in pedagogical inovation in the university context.

KEYWORDS: Pedagogical innovation. Curriculum. Interculturality. University.

RIAEE - Revista Ibero-Americana de Estudos em Educação, Araraquara, v. 13. n. esp. 2, p. 1301-1319, set., 2018. ISSN: 1982-5587. 


\section{Introdução}

A Universidade, como dita a tradição, reconhecida como instituição educacional sede da produção e distribuição do conhecimento científico, têm sofrido compulsoriamente ao longo das últimas décadas críticas referentes à sua estrutura e dinâmica com características burocráticas e pouco flexíveis quanto ao modo de fazer ciência, na construção e aceitação de novos saberes e conhecimentos.

Esse fato tem, sem dúvida, provocado abalos na sua estabilidade e credibilidade enquanto gestora da ciência voltada para os novos tempos, onde a diversidade cultural que toma visibilidade no seu entorno se faz presente entre seus muros, estimulada pelas políticas públicas de ampliação e interiorização do ensino superior e pelas políticas de ações afirmativas. Nessa ótica, vem trazendo desafios para se pensar a universidade e a formação das novas gerações que a ela vem adentrando.

Essa atmosfera de multiculturalidade desafia os modelos epistemológicos tradicionais que norteiam as estruturas dos currículos que ainda dominam e dão base para práticas, procedimentos pedagógicos e construção de conhecimentos a partir da racionalidade técnica, de característica unidirecional, homogeneizadora e etnocêntrica, na universidade.

Diante disso, compreendemos que hoje a universidade carece de práticas formativas inovadoras sistemáticas que instiguem o pensamento e construção de conhecimentos plurais, independentes e/ou divergentes, como requer uma educação onde a multiculturalidade seja levada em conta não como grupos distintos e distantes entre si, mas como grupos e pessoas cujas diferenças e culturas constroem identidades próprias em constante geração de novas sociabilidades nesse campo social múltiplo.

As metas 12.7, 12.9 e 12.13 presentes no Plano Nacional de Educação (2014-2024), Lei n. $^{\circ}$ 13.005/2014, indicam que um dos principais desafios das políticas educacionais no Brasil ainda é a ampliação do acesso das classes sociais menos favorecidas ao ensino superior. Essas políticas de ampliação e interiorização do ensino superior, assim como as das ações afirmativas, estimularam o acesso de diferentes grupos sociais, tanto docentes como discentes, à universidade, gerando uma atmosfera de multiplicidade relacional desses grupos. A existência dessa multiculturalidade, numa perspectiva intercultural, tende a gerar novas sociabilidades no campo social e essas novas sociabilidades se tornam desafiadoras para a pedagogia universitária à medida que esses grupos têm histórias, saberes e práticas individuais e coletivas que se entrecruzam, enunciando uma ecologia de saberes. 
Desta forma, mediante a multiplicidade de identidades e culturas que marcam mais e mais presença na universidade atual, evidenciando as mudanças significativas que vêm ocorrendo na sociedade, não cabe mais entender que a partilha do conhecimento do legado científico-cultural da humanidade - construído sob o prisma da dominação cultural - com as novas gerações detenha a maior parte das atividades da universidade, mesmo que ela seja também válida. A universidade deve, de fato, reinventar-se, aprendendo a construir novas formas de fazer ciência, sob variados modos, rompendo com as barreiras culturais impostas pelo modelo dominante. Portanto, à universidade cabe permitir e proporcionar oportunidades para novas construções de conhecimentos em um processo permanente e proposital, ampliando sua visão sobre o contexto emergente.

Assim, nessa prerrogativa reside a ideia de nos debruçarmos sobre a inovação curricular na universidade, procurando observá-la sob a perspectiva da interculturalidade e da inclusão social.

Compreendemos que a inovação pedagógica está associada ao processo de aquisição e alteração do conhecimento no currículo e às maneiras e condições em que elas ocorrem. As decisões curriculares são frutos de relações conflituosas que disputam território, identidade, autonomia e autoridade curricular. Sendo assim, o currículo é um campo de política cultural que dá sustentabilidade ao percurso de alocação e relocação necessária para gerar as inovações pedagógicas.

Em 2015, iniciamos um estudo sobre o curso de Licenciatura Intercultural Magistério Indígena Tremembé - MITS, promovido no período de 2008 a 2013, pela Universidade Federal do Ceará/Brasil e, reconhecido pelo Ministério da Educação Brasileiro. O curso teve a duração oficial de 4 (quatro) anos e habilitou 36 (trinta e seis) professores da comunidade Indígena Tremembé ao exercício do Magistério Indígena docência e gestão - nas Escolas Indígenas Diferenciadas de Ensino Fundamental e Médio Tremembé.

As escolas indígenas diferenciadas surgiram da necessidade de uma escola que respeitasse a cultura e o jeito de ser índio Tremembé, isto devido à discriminação que as crianças indígenas sofriam nas escolas convencionais. Mediante essa realidade, em 1999, a comunidade Tremembé decidiu não matricular suas crianças nas escolas convencionais, e sem nenhum apoio de parceiros, criaram a primeira experiência de escola diferenciada indígena Tremembé, na comunidade da Praia, em Almofala, distrito de Itarema, localizado 
no Estado do Ceará/Brasil. Começou, então, a luta por uma educação diferenciada nos aldeamentos das comunidades indígenas.

Este estudo teve por objetivo analisar os princípios e procedimentos da experiência curricular do curso MITS, a partir dos registros documentados e do olhar dos protagonistas que participaram do processo de construção e desenvolvimento do seu currículo.

Nossa análise apreciou as diretrizes e os propósitos do Projeto Político Pedagógico (PPC), o Relatório de Avaliação do Ministério da Educação - MEC/SESU para o reconhecimento do curso, documentos institucionais e depoimentos de cursistas, coordenador do curso, lideranças da comunidade Tremembé e representante de uma instituição parceira que participou da experiência em estudo. A pesquisa teve abordagem qualitativa, com pesquisa documental, entrevistas em grupo focal, e observação participante em encontros com a comunidade Tremembé.

A relevância da pesquisa está na análise de uma experiência singular de construção curricular para a formação de professores, em nível superior, nos propósitos de uma licenciatura intercultural sob a ótica da inovação pedagógica. A concepção políticopedagógica do MITS foi além do seu objetivo inicial, formar uma turma de professores indígenas Tremembé, e se constituiu em uma experiência inovadora de construção de dispositivos de interculturalidade, bem como de prática, política e cultura de inclusão no ensino superior brasileiro, sugerindo ainda, mesmo que em micro escala, um novo modo de se fazer universidade, como assim reconheceu e publicou a Comissão de Avaliação do MEC em seu relatório (MEC, 2015). Entendemos que o MITS representou para o contexto universitário uma experiência curricular inovadora potencializadora da interculturalidade e da inclusão social na universidade.

\section{Inovação curricular como experiência epistemológica intercultural}

As concepções de conhecimento e sociedade nos últimos tempos passaram por alterações que, segundo Santos (2004), foram sendo percebidas de forma mais efetiva no processo de mercantilização do conhecimento científico. Entretanto, as implicações provocadas por essas transformações têm surtido efeito contrário, e as consequências são muitas, inclusive de cunho epistemológico. Isto porque a natureza do conhecimento produzido nas universidades tem um caráter eminentemente disciplinar, homogêneo, organizado hierarquicamente, portanto, descontextualizado das necessidades das 
comunidades envolvidas, o que deixa claro a distinção deste diante os outros tipos de conhecimento existente. Desta forma, os problemas a serem estudados são determinados pelos pesquisadores que partilham os mesmos objetivos, onde sua autonomia, por vezes, pode provocar ausência de responsabilidade social, frente aos resultados que esse conhecimento produz.

Para Santos (2006), é dessa forma que a universidade tem contribuído para a "monocultura do saber". Para o autor, esta é uma das formas mais poderosas de negação e desqualificação de tudo aquilo que está fora dos critérios de verdade da ciência moderna. A Universidade é o espaço onde os cânones da ciência se consolidam como exclusivos da produção de conhecimento, sendo que qualquer conhecimento produzido fora dos seus muros é classificado de "ignorância".

A história da Universidade tem sido marcada por esse tipo de conhecimento, no entanto, o cenário atual em que a mesma está inserida passa a exigir dela um novo modelo de conhecimento, que Santos (2004) denomina de "conhecimento pluriversitário".

O conhecimento pluriversitário, diferentemente do universitário, é um conhecimento contextual na medida em que o princípio organizador da sua produção é a aplicação que lhe pode ser dada. Partindo desse pressuposto, ele é o resultado do diálogo entre universidade e comunidade, haja vista que sua utilização ocorre nos extramuros das IES e, os objetivos propostos e a determinação dos problemas que busca resolver são resultados desse diálogo. Ele é caracterizado como um conhecimento transdisciplinar, contextualizado e heterogêneo, na medida em que tem que dialogar com as outras formas de conhecer e é mais flexível de ser produzido em sistemas abertos sem uma estrutura hierárquica rígida.

Assim sendo, todas as prerrogativas atribuídas ao conhecimento universitário são questionadas pelo conhecimento pluriversitário. Na verdade, é a própria relação entre ciência e sociedade que é colocada em questão, visto que a sociedade deixa de ser um mero objeto da ciência, para ser ela própria sujeito de observações da ciência.

Esta nova proposição de conhecimento provoca no seio da universidade uma desestabilização da especificidade institucional atual à medida que interrompe sua hegemonia e legitimidade e a leva a uma avaliação por critérios diferentes dos adotados até então. Neste âmbito, o conhecimento pluriversitário tem sido apresentado como a forma de concretização dessa nova perspectiva vislumbrada para o conhecimento, nas parcerias 
estabelecidas entre as universidades e as indústrias, sob a forma de conhecimento mercantil.

Em alguns países, principalmente nos centrais e semiperiféricos, este modelo não tem sido aplicado na perspectiva mercantil, e sim de forma cooperativa, solidária, através de parcerias estabelecidas entre pesquisadores e sindicatos, organizações não governamentais, movimentos sociais, grupos sociais especialmente vulneráveis e comunidades populares, representando um número significativo de utilizadores, que vão construindo uma nova relação com a ciência e a tecnologia, provocando assim a necessidade de uma participação na sua produção e avaliação dos seus impactos.

Outro aspecto que vale ressaltar é o surgimento do conhecimento pluriversitário nas universidades nos países pluriétnicos a partir da entrada de grupos minoritários, que ao ingressarem nas universidades percebem que a sua inclusão é, na verdade, uma forma de exclusão, pois se deparam com a desvalorização em relação ao seu conhecimento, trazido de seus grupos originários. Esta nova realidade vivenciada pela universidade provoca confrontos entre o conhecimento científico e outras formas de conhecimento, e aumenta sua responsabilidade social.

No conhecimento pluriversitário a ênfase centra-se no sujeito do conhecimento, tirando a exclusividade das universidades. Nele, os movimentos sociais deixam de ser vistos como objetos de conhecimento das ciências humanas, e passam a se assumir como sujeitos de sua práxis social, formulando interpretações dos significados de seus projetos e elaborando deliberações autônomas em torno de suas lutas. Este fato leva as universidades a reconhecerem as diferentes formas de conhecimento, redimensionando a relação entre universidade e sociedade.

Neste cenário, as práticas de extensão universitária que, ao longo dos anos, foram consideradas como experiências secundárias no contexto das universidades e, portanto, pouco valorizadas em detrimento da pesquisa, podem vir a exercer papel análogo ao da política social, quando passam a ser vistas como possibilidades de amenizar e minimizar as desigualdades sociais para assegurar a estabilidade do sistema, apresentando condições de inverter os objetivos para os quais foram instituídas. Para Fagundes (1985), a extensão universitária, apesar do sistema lhe atribuir uma perspectiva conservadora e domesticadora, é considerada um espaço de contradição onde se podem gerar novos projetos de universidade articulados com o processo de transformação social. 
Compreendemos que a extensão universitária é potencializadora do conhecimento pluriversitário se gestada numa perspectiva invertida. A “extensão invertida” (SANTOS, 2008) não acena para um único sentido, ou seja, da universidade para a comunidade, pois esta visão não garante novas possibilidades de anulação do status de contradição estabelecido por aqueles que definem os rumos da universidade.

A “extensão invertida" possibilita mudança de paradigma no processo de ensinar a aprender, justamente por ser o espaço de encontro entre os diversos tipos de saberes, dos alunos, comunidade e professores. Ao provocar uma reflexão sobre as práticas que são constituídas através das experiências, gera um novo senso comum numa ecologia de saberes. A ecologia dos saberes é "uma forma de extensão ao contrário [...]. Consiste na promoção de diálogos entre o saber científico e saberes leigos, populares, tradicionais, provindos de culturas não ocidentais (indígenas, africanas, orientais, etc.)" (SANTOS, 2008, p.53). Desta forma, as aprendizagens na extensão serão dotadas de significado quando vistas no poder de criação e recriação de conhecimento.

Diante desses aspectos, observa-se que a dinâmica curricular, no contexto da extensão universitária, trilha na direção de mudanças, evocando novos caminhos, agindo como mediador - includente das relações sócio afetivas, abrindo-se para o protagonismo epistemológico e reconhecendo novas autorias na perspectiva da produção do conhecimento. A extensão universitária, ao potencializar o conhecimento pluriversitário, incita a inovação curricular porque reconhece outras formas de produção de saberes, incorpora a dimensão sociohistórica do conhecimento; incentiva a gestão partilhada dos atos pedagógicos com ações reflexivas e compreende o conhecimento com algo complexo e passível de reconfigurações. Ela produz cenários de justiça curricular.

Compreende-se o currículo como território cultural que envolve saber e poder, disputa formas de subjetividades, demarca diferenciações e presenças, produz exclusões, saberes e verdades acerca de como pensar ser e agir. Desenha regras e raciocínios. Produz formas de regulação e de emancipação. Contextualiza e recontextualiza discursos: oficial e institucional (BALL, 1994/2001). O currículo é uma arena complexa, conflituosa, processual de inclusão e exclusão social, pois é um campo de conflito entre o oficial/institucional e o emergente.

Nossa compreensão é de que a inovação curricular não acontece nas novas práticas para adaptação aos processos regulatórios no sentido de produzir melhorias educacionais esperadas, mas sim na emergência de experiências interculturais que se propõem enfrentar 
toda a dificuldade decorrente da presença paradigmática dominante e age contra um modelo político que impõe a homogeneização como uma única forma de ensinar, aprender e produzir conhecimento.

A inovação curricular tem uma intencionalidade política clara de inclusão social pela corporificação da interculturalidade, pela criação de zonas de relações interculturais e pela produção de novas/outras/diferentes identidades. Ela corporifica formas particulares de inovações pedagógicas (agir, sentir, falar e ver o mundo e o "eu”). Sustenta experiências epistemológicas interculturais. Dá visibilidade à "inquietude" e potencializa a energia inovadora.

A inovação curricular são percursos discursivos que reconhecem a diferença nas relações sociais. São caminhos que permitem experiências interculturais desenhando cenários de interculturalidade e inclusão social. O propósito político da inovação curricular é movimentar territórios culturais, portanto, tem uma intencionalidade política clara de reconhecer as relações, por vezes contraditórias, entre pensamento e emoção, privilegiando as relações de amorosidade, cumplicidade, carinho e sedução; permite-se escutar, esperar e analisar criticamente ao mesmo tempo, sem deixar cessar o movimento da construção do conhecimento.

A construção do currículo inovador é mediada por relações participativas e democráticas onde múltiplas fontes de autoridades disputam ideias, mudanças e reformas na educação. Por conseguinte, são relações capazes de mediar conflitos, negociar estratégias para o fortalecimento das experiências e desenvolver compreensões valorativas e habilidades para tratar com a complexidade das relações sociais.

Nesse sentido, as relações interpessoais são aprimoradas porque participam das decisões curriculares com posturas reflexivas frente ao poder e ao oficial. As decisões coletivas são sempre pautadas, não necessariamente em algo novo, mas em algo melhor para um determinado grupo, em um determinado contexto sociocultural.

Gestar a inovação curricular requer gerir mudanças conscientes e intencionais com o propósito de transformar o existente, tendo como consequência o desequilíbrio ou a quebra com a estrutura vertical de poder. O princípio inovador só permanece se o processo de mudança se pautar em ideias públicas (para todos) de educação, porque nelas reside o propósito da inclusão e da interculturalidade.

Como bem explica Paraíso (2015), o currículo como território de culturas potencializa a cultura que "está por vir". A cultura é um modo de vida de um grupo, 
material acumulado e estabelecido, produz, é produzida e é produto, ao mesmo tempo, e está sempre pronta a transgredir o currículo. O currículo transgressor legitima e dá visibilidade às experiências epistemológicas interculturais, tornando-se inovador.

A inovação curricular configura-se como uma experiência epistemológica intercultural porque possibilita a produção do seu próprio saber, o saber da experiência. Para Larrosa Bondia (2002), a experiência é o que nos acontece, que nos transforma. Aquilo que "nos passa" e não o que "se passa". É o parar para pensar, escutar, olhar, sentir, pensar devagar, demorar-se nos detalhes, cultivar a atenção, aprender a lentidão, falar sobre o que nos acontece, cultivar a arte do encontro, dar-se tempo. O saber de experiência é o sentido do que nos acontece. Então, o saber de experiência revela o sentido ou sem sentido da nossa existência.

Se a experiência é o que nos acontece e se o saber de experiência tem a ver com a elaboração do sentido ou do sem sentido do que nos acontece, trata-se de um saber finito, ligado à existência de um indivíduo ou de uma comunidade humana particular. Trata-se de um saber que revela ao homem concreto e singular o sentido ou sem sentido de sua própria existência. Por isso, o saber da experiência é um saber particular, subjetivo, relativo, contingente e pessoal (LARROSA BONDIA, 2002).

A inovação curricular requer experiências reinventivas de ensinar e aprender. São experiências criadoras de novas formas de sociabilidades. Formas diferenciadas de se comunicar e se relacionar. Formas de inventar-se e reinventar-se. Nesse movimento de inventar e reiventar-se que a "inventabilidade da diferença" (BALL, 2001) acontece.

$\mathrm{O}$ ato de invertar-se e reinventar-se é um ato político para enfraquecer as hierarquias epistemológicas da racionalidade técnica, científica e instrumental e fortalecer as identidades fronteiriças. Portanto, a inovação curricular sempre é intencional e carrega o ônus da complexidade da iniciativa, pois pressupõe um pensamento pedagógico transformador. A inovação curricular, enquanto processo de corporificação da experiência epistemológica intercultural, transforma-se em poder criativo da inovação pedagógica.

\section{A experiência curricular do curso Magistério Indígena Tremembé Superior}

A Licenciatura Intercultural - Magistério Indígena Tremembé Superior (MITS) foi oficialmente criada pela Resolução Ad Referendum/CEPE/UFC, de 04 de agosto de 2008, da Universidade Federal do Ceará. O curso teve a duração oficial de 4 (quatro) anos.

RIAEE - Revista Ibero-Americana de Estudos em Educação, Araraquara, v. 13. n. esp. 2, p. 1301-1319, set., 2018. ISSN: $1982-5587$. 
Embora o seu propósito inicial fosse formar 39 (trinta e nove) professores das escolas públicas Diferenciadas de Ensino Fundamental e Médio Tremembé para o exercício da docência e gestão do Magistério Indígena, concluiu habilitando 36 (trinta e seis) professores para esse exercício. O curso foi criado pela Universidade Federal do Ceará como parte das políticas para a inclusão dos povos indígenas no ensino superior e teve o apoio do Programa de Apoio à Formação Superior e Licenciaturas Indígenas PROLIND, promovido pela Secretaria de Educação Continuada, Alfabetização, Diversidade e Inclusão do Ministério da educação - SECAD/MEC.

Iniciamos esta pesquisa pela análise documental, que objetivou compreender os caminhos percorridos para o delineamento do currículo oficial do curso, bem como as diretrizes para sua operacionalização. Optamos pela pesquisa qualitativa por essa permitir captar os discursos, os depoimentos dos sujeitos no contexto pesquisado e a observação participante. Com base nas informações obtidas pelos documentos oficiais do curso, elaboramos um roteiro de entrevista aberta que orientou a conversa com um grupo focal que teve a participação de dez (10) representantes da comunidade indígena Tremembé, dos quais, nove (09) são egressos do curso MITS, desses, dois (02) são lideranças da comunidade Tremembé, e um (01) representante de uma instituição parceira. Com esse grupo realizamos entrevista semiestruturada e observamos suas manifestações nas reuniões e encontros que ocorriam na comunidade Tremembé. Como procedimento de registro, escolhemos gravação em áudio.

O objetivo das entrevistas e observações foi confrontar informações contidas no projeto pedagógico e no relatório de avaliação do curso e, também, captar o olhar dos sujeitos participantes a respeito do processo de construção curricular do curso.

A partir da análise do Projeto Pedagógico do Curso identificamos elementos que sugerem pistas de investigações pertinentes sobre as potencialidades inovadoras curriculares para o contexto universitário, bem como de inclusão social e de interculturalidade, suscetíveis de subsidiar políticas públicas internas às Instituições de Ensino Superior - IES. Os propósitos pedagógicos do curso de Licenciatura Intercultural fortaleceram a educação Tremembé em um contexto de sistema educacional que prima pelo controle e pela negação de identidades e de culturas, sendo assim, o MITS se tornou uma experiência epistemológica intercultural singular.

Consideramos que o MITS experienciou a construção de um currículo inovador no ensino superior porque nasceu na e para a comunidade de índios Tremembé. Surgiu no seio 
da coletividade Tremembé e ao ser institucionalizado pela universidade não perdeu sua identidade e autoridade curricular. Feito isso, desafiou a instituição de ensino ao gerar novas formas para oficializar, executar e reconhecer o curso. Ele não foi um curso que iniciou no gabinete da universidade, tampouco seus principais atores foram docentes e pesquisadores universitários titulados. Foi um curso construído por muitas mãos e protagonizado pela comunidade Tremembé (lideranças tradicionais, professores das escolas, pais e mães de alunos, jovens e até mesmo crianças), apoiadores (entre os quais a Prefeitura Municipal de Itarema/CE e a SEDUC) e parceiros (entre os quais docentes da UFC e de outras IES).

Entendemos que o processo democrático só é legítimo se o tempo dos seus agentes for respeitado, e neste sentido é importante destacar que, apesar do MITS ter sido criado oficialmente na universidade em 2008 (ad referendum), o desenho do seu projeto se iniciou em 2006, durante o I Seminário Magistério Indígena Tremembé Superior - SEMITS. De 2006 a 2008 outros seminários ocorreram até a configuração final do Projeto Pedagógico do Curso. As decisões curriculares tomadas nos seminários transformavam-se em experiências pedagógicas como uma forma de experimentação e avaliação permanente do currículo. Segundo o coordenador do curso: “o currículo do MITS foi uma construção coletiva e aberta, com o fiel propósito de ser aperfeiçoado a cada SEMITS”.

Como já foi dito, a construção do currículo do MITS foi um processo coletivo com a participação da comunidade Tremembé. Consideramos que esse processo democrático significou um marco curricular importante para a formação específica de professores que a escola diferenciada Tremembé reivindicava. Mas, também, representou uma ruptura com o paradigma curricular universitário na medida em que reconheceu a pluralidade, a autonomia, a articulação sistêmica e a dinâmica horizontal dos saberes Tremembé. Os saberes Tremembé, ao serem oficializados no currículo universitário, transformaram o conhecimento em interconhecimento, em reconhecimento e autoconhecimento (SANTOS, 2006).

O MITS representa uma experiência de inovação pedagógica porque não nasceu dentro da universidade, mas reivindicou dela o seu compromisso social. Na visão dos Tremembé, a certificação não era o principal objetivo, mas o reconhecimento dos seus saberes e comprometimento com a sua luta identitária. 
Foi muito importante porque ele ajudou muito o povo Tremembé se fortalecer na questão de sua luta, porque a gente tinha a participação de muitas lideranças. (liderança e cursista 1).

Nós que era os cursistas demos nossa contribuição dizendo o que a gente queria estudar, qual conteúdo estudar (liderança e cursista 2).

A construção curricular do curso MITS desafiou a universidade a reconhecer a relevância da extensão universitária numa perspectiva epistemológica. Castro (2004) considera que a extensão tem a capacidade de produzir conhecimento a partir da experiência e possuir algumas características que, se bem exploradas, podem vir a contribuir para uma mudança no processo de ensinar e aprender: possuem um arsenal metodológico diferenciado; é feita de encontros entre alunos, professores e comunidades; tem a possibilidade de, neste encontro, incorporar outros saberes, de criar um novo senso comum e de ampliar a capacidade de reflexão sobre as práticas, porque nelas se constituem, ou seja, são constituídas pelas experiências.

Neste sentido, o currículo universitário passa a ser epistemologicamente contaminado pela sociedade em um processo de partilha e troca de experiências. E, nesse contexto, novas formas de produzir, ensinar e aprender o conhecimento serão necessárias.

O projeto do MITS reivindicou da universidade o reconhecimento da "extensão invertida" como via de mão dupla. Ao se colocar como projeto coletivo, territorializado, desenhado por uma "ecologia de saberes", com uma intencionalidade política clara de inclusão social, o MITS desafia a racionalidade científica do currículo universitário a se reinventar, gerando microrrupturas, mesmo que momentâneas, com suas crenças paradigmáticas. Afirma-se que o MITS nasceu e se manteve no pilar da extensão universitária porque seu currículo foi feito:

[...] a muitas mãos, construído no dia a dia da comunidade, na vivência dos professores Tremembé em sala de aula e na convivência com os docentes, e apoiadores deste projeto, marcado pela especificidade, construção coletiva e interculturalidade". (representante da instituição parceira).

O projeto do MITS, por se sustentar no pilar da extensão universitária “invertida", propõe uma nova forma de se relacionar com o conhecimento no seio da universidade. Desestabiliza a especificidade institucional à medida que interrompe sua hegemonia e legitimidade e a leva a uma avaliação por critérios diferentes dos adotados até então. $\mathrm{O}$ curso em questão desenhou um caminho de ensino-aprendizagem consonante às necessidades e intencionalidades da comunidade que o produziu, portanto, um currículo 
diferente do que a universidade, dentro da sua racionalidade, poderia oferecer. Um caminho onde o conhecimento universitário sozinho não tem lugar. Um caminho que precisa da pluralidade e da interculturalidade de saberes como formas de construção de conhecimento. É nesse sentido que se reconhece o currículo do MITS como inovador, porque ele se reconhece no processo democrático.

A organização curricular do MITS representa a maneira de pensar Tremembé, assim como o de fazer sua vida em comunidade. $\mathrm{O}$ desafio foi organizar o conhecimento em componentes curriculares disciplinares sem, no entanto, comprometer esta visão Tremembé. Observamos que o desafio foi superado ao optarem por fazer divisão do currículo em eixos. Tais eixos são denominados de saberes, estes por sua vez fundamentam "[...] o ensino-aprendizagem não somente em conhecimento científico, mas também em sabedorias da cultura indígena que eles consideram importantes [...]". "O eixo é uma tentativa de juntar o que a disciplina separa" (PPPC/ MITS, 2008, p.29). As quatro mil horas, desenvolvidas durante oito semestres, ao longo de quatro anos oficiais do curso, somados aos dois anos de discussão, reflexão e elaboração do projeto do pedagógico do curso, representam um processo de aprender como aprender e ensinar.

A proposta curricular do MITS se opôs a um currículo excludente. Seu princípio nasceu na afirmação de luta por uma educação diferenciada da escola convencional, respeitando o direito de pensar, ser e criar da cultura indígena, vinculados aos saberes e valores indígenas (PPPC/ MITS, 2008). Os cursistas entrevistados afirmaram que um dos desafios curriculares do MITS foi promover a articulação dos saberes indígenas com o arcabouço dos conhecimentos técnico-científicos, dos fundamentos legais, legitimados pela Universidade e da política dos sistemas de ensino sobre a formação do professor.

A gente sempre costuma dizer que o Tremembé, ele tem o dobro da carga do branco, porque o branco ele aprende só o convencional, e o Tremembé tem que aprender os dois lados: o convencional e o da comunidade, específico Tremembé. (cursista 5)

Pelos depoimentos dos cursistas, o desafio permanente foi o exercício de reflexões críticas em relação aos conhecimentos advindos do planejamento do professor universitário e a realidade do índio Tremembé, envolvendo costumes e saberes dos índios, em um movimento de inserção dos conhecimentos indígenas, de maneira mais consistente, no processo de formação.

RIAEE - Revista Ibero-Americana de Estudos em Educação, Araraquara, v. 13. n. esp. 2, p. 1301-1319, set., 2018. ISSN: 1982-5587. 
Porque às vezes tinha coisa que a gente achava interessante estudar e não tava colocado no plano. Então era feito o acréscimo. Aí tinha coisas que a gente achava que não era tão interessante, a gente acaba tirando. E era assim. (cursista 6)

Esse desafio permanente foi o movimento necessário para se efetivar o currículo como território intercultural, onde o processo mobilizador de inovação curricular foi protagonizado pelos Tremembé e pela universidade.

E é uma coisa muito interessante, porque essa escola desde o início, eu mesmo nessa experiência como pesquisador estando com eles, ela vai ser mobilizadora de intelectuais, de pesquisadores, de profissionais no sentido de construir um espaço de reflexão, de produção mesmo científica, intelectual a respeito desse processo". (coordenador do curso)

O MITS, segundo seus alunos egressos entrevistados, foi importante para eles porque significou um aprendizado coletivo sobre sua etnia e cultura, vindo a se constituir como uma ferramenta valorosa para fortalecer a luta do povo Tremembé, reconhecendo que importância não foi somente para o cursista do MITS, mas também para toda a comunidade do aldeamento, que participou ativamente da sua construção. Para os cursistas e lideranças, o MITS significou o "compromisso dos jovens Tremembé com a luta do seu povo, reafirmando o compromisso da educação Tremembé que surge da luta e se volta para a luta" (cursista e liderança 1).

Os cursistas afirmaram ainda que a construção e a vivência do MITS lhes permitiram adquirir segurança em relação aos saberes Tremembé. Segundo o cursista entrevistado: "Hoje, a gente é diferente de antes. Porque a gente confia naquilo que tá repassando. Porque a gente sabe que sabe" (cursista 3). Esse sentimento de confiança que os cursistas indígenas expressaram em suas falas se deve ao fato de terem conhecido de forma mais intensa saberes da etnia através de suas próprias vivências em experiências culturais marcantes durante o curso.

O povo Tremembé mantém uma tradição oral relacionada ao caráter sagrado da natureza, às crenças e aos mitos, cujas histórias são contadas pelos mais velhos. $\mathrm{O}$ aprender com os mais velhos foi uma importante contribuição do MITS na formação dos cursistas, como afirma um cursista: “aí, na disciplina Contação de História, teve a história do trancoso, teve as histórias de luta pela terra, que isso assim foi muito forte porque teve as vivências dos mais velhos. Essa disciplina marcou profundamente".

Outra disciplina do curso, onde se fez a explicação do significado do Torem mediada pelo conhecimento científico, levado pela universidade, permitiu aos cursistas 
desenvolverem um olhar diferenciado sobre essa prática cultural. Desta forma, entendemos que a reconfiguração do saber Tremembé evidenciou uma experiência epistemológica intercultural porque possibilitou a produção do seu próprio saber a partir do diálogo com os diferentes saberes (científico, Tremembé, políticos entre outros).

[...] enquanto a gente tava dançando o Torem é um sentimento. E, quando a gente tá ouvindo os relatos do Torem é outro sentimento [...] Então, a partir dessa disciplina a gente também adquiriu um saber a mais, e um olhar diferente do Torem". (cursista 1)

O Torém é um ritual de dança de roda acompanhada de cantos, ao som do Maracá. Durante a dança se consome uma bebida fermentada de caju, conhecida como mocororó. Por meio da música e da coreografia, o Torém ritualiza as relações dos ancestrais com os animais e as plantas, tendo se tornado o símbolo político da afirmação étnica dos Tremembé contemporâneos (Oliveira Júnior, 1998). Para o povo Tremembé, a dança do Torém representa sua marca identitária e, como afirma o coordenador do MITS, o "Torém tem tido o papel assim muito relevante nesse processo todo na construção de uma educação diferenciada indígena Tremembé".

O currículo do MITS possibilitou que os cursistas promovessem reflexões críticas em relação aos conteúdos advindos da realidade do índio Tremembé, que puderam auxiliar em sua formação e, por fim, colocar em efetiva prática e em movimento a inserção dos conhecimentos indígenas de maneira mais consistente, envolvendo costumes e saberes dos índios.

A partir das análises, e com base em Santos (1996 e 2008), podemos afirmar que o MITS apresentou elementos identificados na origem de transformações resultantes do processo de lutas e de reivindicações reconhecido como ruptura epistemológica. Reconhece-se, também, que obteve o reconhecimento e adesão de outras maneiras de conhecer, outras formas de produção de saberes, incluindo a dimensão sócio-histórica do conhecimento, assim como a dimensão que inter-relaciona o sujeito e o objeto.

\section{Considerações finais}

Mediante a história do conhecimento científico e a tensão entre o modelo tradicional de ciência e o reconhecimento crescente dos saberes práticos produzidos pelas diferentes populações, intensificando a preocupação com o papel social das universidades,

RIAEE - Revista Ibero-Americana de Estudos em Educação, Araraquara, v. 13. n. esp. 2, p. 1301-1319, set., 2018. ISSN: $1982-5587$. 
consideramos que o MITS apresentou uma ruptura paradigmática curricular, pois se caracterizou como um curso intercultural, que desde o seu projeto foi construído por aqueles que fazem a comunidade indígena Tremembé.

O curso foi pensado e realizado no exercício do diálogo intercultural com professores, alunos cursistas, colaboradores e todos os participantes da aldeia, em assembléias, seminários e salas de aula, levando em conta os saberes da etnia, valorizando o conhecimento das lideranças indígenas aprendidos na experiência cotidiana na comunidade, nas tradições e interações com os elementos culturais da etnia e na vivência de embates ocorridos nos tempos passados.

Consideramos que o MITS se apresenta com características da inovação curricular, visto que estimula uma racionalidade que alimenta e é alimentada por um currículo mediador-includente das relações afetivas como condição da aprendizagem. Um currículo que se abre para o protagonismo epistemológico, reconhecendo novas autorias na perspectiva da produção do conhecimento.

Nesse caso, é um currículo que objetiva a inovação pedagógica na universidade, que passa, obrigatoriamente, por uma experiência epistemológica intercultural, e se afasta consideradamente do enfoque da racionalidade técnico-academicista, que apesar de muito criticado, se mantém tradicionalmente como o usual no ensino superior, onde fica evidente a distância entre conhecimento teórico e conhecimento prático aplicado.

No rastro desta análise, consideramos que o MITS traz um exemplo para o contexto universitário, onde se tem uma evidente valorização do protagonismo dos sujeitos envolvidos na aprendizagem e uma abertura para o diálogo intercultural no enfrentamento de desafios na busca do conhecimento, observando o fomento do processo de aprender e ensinar dentro de um ambiente do conhecimento contextualizado, colaborativo, e numa contínua aproximação com a realidade como ela se encontra.

Diante do exposto, cremos que compete à universidade diante das novas perspectivas apontadas reinventar-se, à medida que é impactada por experiências como as caracterizadas nas discussões deste estudo, buscando rupturas epistemológicas que construam estrutura curricular inovadora, dando passos seguros para a inovação pedagógica no contexto universitário em tempos interculturais.

\section{REFERÊNCIAS}


BALL, S. J. Diretrizes políticas globais e relações políticas locais em educação. Currículo sem fronteiras, Porto Alegre, 2001. v. 1 n. 2, p. 99-116, jul./dez., 2001

BALL, S. J. Educationalreform: a criticaland post-structural approach. Buckingham: open University Press, 1994.

BONDÍA, J. L. Notas sobre a experiência e o saber de experiência. Revista Brasileira de Educação, n.19, p. 22-29, jan/fev/mar/abr., 2002.

BRASIL. Ministério da Educação. Relatório de avaliação de Curso presencial do Curso de licenciatura intercultural Magistério Indígena Tremembé Superior. Brasília, 2015.

CASTRO, Luciana Maria Cerqueira. A universidade, a extensão universitária e a produção de conhecimentos emancipadores. In: Anais... REUNIÃO ANUAL DA ANPED, 27, Caxambu, 2004.

MESSEDER. M. L. L. Etnicidade e ritual Tremembé: construção da memória e lógica cultural. Revista de Ciências Sociais, FORTALEZA, v. 43, n. 2, p. 32 - 42, jul./dez., 2012.

OLIVEIRA JUNIOR, Gerson A. de. Torém: brincadeira dos índios velhos. São Paulo, Annablume, 1998.

PARAÍSO, M. A. Currículo, cultura e diferença: quando o amor entra em cena. In: MORGADO, J. C; MENDES, G. L.; MOREIRA. A. F.; PACHECO, J. A. (Orgs). Currículo internacionalização cosmopolitismo: desafios contemporâneos em contextos luso-afro-brasileiros. Santo Tirso: De Facto editores, 2015.

PROJETO POLÍTICO PEDAGÓGICO. Curso Magistério Indígena Tremembé Superior - MITS (Licenciatura Intercultural). Universidade Federal do Ceará - UFC, 2008.

SANTOS, B. de S. Pela mão de Alice: o social e o político na pós-modernidade. São Paulo; Cortez, 1996.

SANTOS, B de S. A critica da razão indolente: contra o desperdício da experiência. São Paulo; Cortez, 2004.

SANTOS, B. de S. A Gramática do Tempo. São Paulo: Cortez, 2006.

SANTOS, B. de S. A universidade no século XXI: para uma reforma democrática e emancipatória da Universidade. São Paulo: Cortez, 2010.

SANTOS, B. de S., ALMEIDA FILHO, N. A Universidade no século XXI: para uma Universidade Nova. Coimbra: Edições Almedina, 2008. 


\section{Como referenciar este artigo}

CAMPANI, Adriana.; SILVA, Rejane Maria Gomes da.; PARENTE, Paulina Maria Mendes. Inovação pedagógica no contexto universitário: a experiência curricular do curso Magistério Indígena Superior. Revista Ibero-Americana de Estudos em Educação, Araraquara, v. 13. n. esp. 2, p. 1301-1319, set., 2018. ISSN: 1982-5587. DOI: 10.21723/riaee.v13.nesp2.set2018.11645

Submetido em: 15/03/2018

Aprovado em: 14/06/2018 